\title{
Deep chronic cutaneous New World leishmaniasis due to Leishmania guyanensis and trichinellosis in a German returnee from Ecuador
}

\author{
Uwe Wollina, André Koch, Alena Bitel
}

Department of Dermatology and Allergology, Städtisches Klinikum Dresden, 01067 Dresden. Germany

Corresponding author: Prof. Uwe Wollina, E-mail: Uwe.Wollina@klinikum-dresden.de

\begin{abstract}
In recent years, leishmaniasis has become more common in Germany due to refugees and returnees from endemic areas. However, New World leishmaniasis is less common. We report a 19-year-old female returnee from Ecuador with relapsing deep cutaneous leishmaniasis relapsing after glucantime and unresponsive to paromycine. Species identification by polymerase chain reaction revealed L. guyanense. We discuss the molecular background for possible treatment failure to first line therapy. The same patient also had an infestation by trichinellosis.

Infestations and infections need to be considered in returnees from endemic areas. Dermatologists play an important role in clinical diagnosis.
\end{abstract}

Key words: Travel medicine; Leishmaniasis; Trichinellosis; South America; Leishmania guyanense.

\section{INTRODUCTION}

Treatment failure and symptomatic relapse are major concerns in New World cutaneous leishmaniasis. Such complications are seen frequently in Leishmania (L.) guyanensis infections, in which patients respond variously to first-line treatment and are at higher risk to develop chronic cutaneous leishmaniasis [1].

Leishmaniasis due to L. guyanensis has been reported from Argentina [2], Brazil [3], Colombia [4], Ecuador [5], and Peru [6].

The Surveillance of Imported Infections in Germany (SIMPID) Surveillance Network reported 42 cases of leishmaniasis in Germany during the years 2001-2004. Most of them were cutaneous diseases acquired in the Mediterranean countries [7]. Harms et al. (2011) analyzed 23 cases of New World leishmaniasis in returnees from Central or South America to Germany. In all cases $L$. braziliensis had been detected by polymerase chain reaction (PCR) [8].

\section{CASE REPORT}

A 19-year-old German Caucasian women returned from a 12-months stay to Ecuador where she developed ulcero-nodular lesions on the nose and arms. New World leishmaniasis was diagnosed. An intralesional treatment with glucantime once a week was initiated in Ecuador. The lesions disappeared within two months. Once months later, nodular lesions occurred on the left cheek. She also reported diarrhea and temporary muscle pain during her stay in Ecuador.

After return from Ecuador 7 months later, she presented to the clinic for further diagnostics with five deep nodular lesions on the left cheek (Fig. 1). At that timepoint, she had no fever, arthralgia or arthritis, no diarrhea. She suffered from mild fatigue.

Routine laboratory investigations were unremarkable except for revealed increased counts of eosinophils in peripheral blood - $80 \mathrm{Gpt} / \mathrm{L}$ (normal range 0-40). Antibodies to leishmania were negative but antibodies

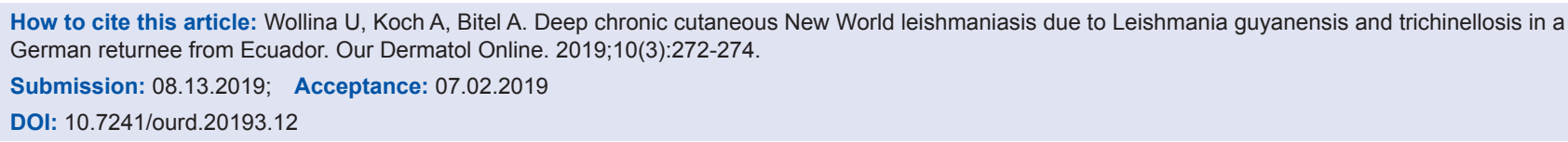




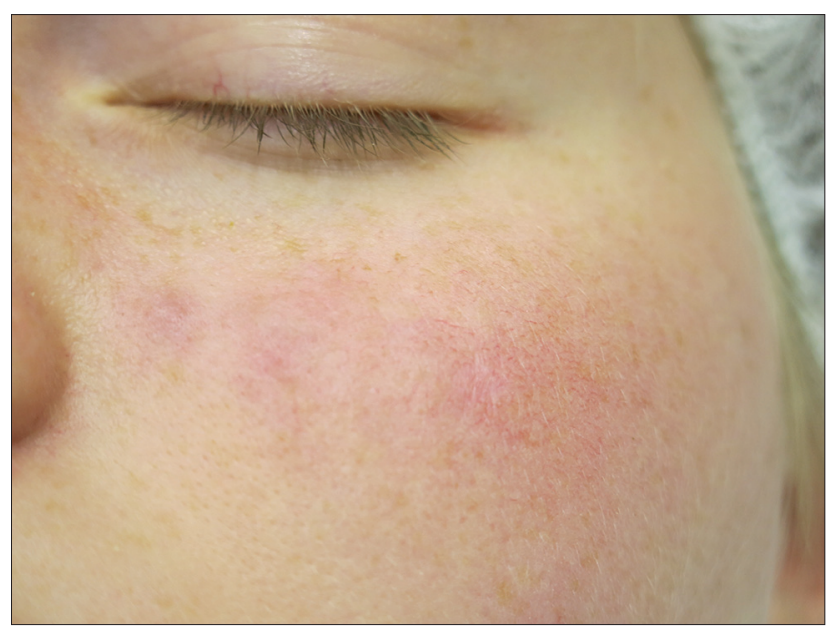

Figure 1: Leishmania guyanensis-infection. Slightly erythematous, deeply seated nodules on the cheek.

against Trichinella were positive. A deep skin biopsy was taken for PCR to leishmania species. PCR was positive for L. guyanensis.

Diagnostic ultrasound demonstrated normal cervical, slightly enlarged axillary and inguinal lymph nodes, and a mild hepatosplenomegaly. Chest-X-ray was unremarkable.

The diagnoses cutaneous leishmaniasis of the New World and trichinosis were confirmed, although hepatosplenomegaly in conjunction with fever is a symptom of visceral leishmaniasis. However, the patient had no fever, leuko- or lymphopenia, anemia or thrombocytopenia. No circulating antibodies could be detected, and her general health status was good.

We started with topical treatment of leishmaniasis after confirmation of Leishmania spp. with paromycin ointment, but it remained unsuccessful. After species identification, we recommended miltefostin $2.5 \mathrm{mg} / \mathrm{kg}$ body weight for 28 days.

In addition, albendazole $400 \mathrm{mg}$ twice daily for 10 days was suggested for trichinellosis treatment.

\section{DISCUSSION}

In Germany, most cases of imported leishmaniasis belong to the cutaneous and mucocutaneous Old World leishmaniasis, while New World tegumental and visceral types are less common [7-10]. The Institute for Tropical Medicine, Berlin, registered in 201516 cases of imported leishmaniasis in Germany including two
New Word leishmaniasis infections from Brazil and Peru [11].

Here we report a case of deep cutaneous L. guyanensis infection relapsing after glucantime in a German returnee from Ecuador. The treatment failures and relapses with this subtype is a challenge.

L. guyanensis shows a limited response to antimony, since they are capable to detoxify peroxides by trypanothione. Ornithine decarboxylase (ODC) and $\gamma$-glutamylcysteine synthetase (GSHl) produce molecules that are direct precursors of trypanothione. Parasites with ODC- or GSHl-overexpression presented an increase of two and four-fold in antimony (III) -resistance index, compared with the wild-type line [12]. Another mechanism involved in antimony resistance are point mutations in the gene encoding aquaglyceroporin 1 [13].

Animal studies revealed that leishmania RNA virus 1 (LRV1), nested within L. guyanensis parasites, is able to exacerbate experimental murine leishmaniasis. LRV1 is recognized by the host Toll-like receptor 3 (TLR3) [14]. The virus induces strong interferon type I immune responses that diminish the level of interferon- $\gamma$ production and release necessary to control leishmania infection [15].

The prevalence of LRVl in human L. guyanensis infection and its relationship to treatment failure and inflammation has been investigated among 75 patients with a diagnosis of primary localized New World cutaneous leishmaniasis. The prevalence of LRVl-positive L. guyanensis infection was $58 \%$. All patients infected with LRVl-negative L. guyanensis responded to a single or double dose of pentamidine. In contrast, 12 of 44 LRV1-positive patients (27\%) presented with persistent infection and symptomatic relapse that required extended therapy and the use of second-line drugs. LRVl presence was also associated with a significant increase in levels of intralesional inflammation. The LRVl status in L. guyanensis infection is predictive of first-line treatment failure and symptomatic relapse [16]. However, we were not able to analyze our sample for LVRl presence.

Our patient also suffered from mild trichinellosis. Trichinella spiralis and T. pseudospiralis occur worldwide. The first one is found in wild and domestic pigs and wild carnivores, the second one infects both mammals and birds. The most important source 
of human infection worldwide is the domestic pig. Infection of humans occurs with the ingestion of Trichinella larvae that are encysted in muscle tissue and is strongly associated with the consumption of raw or undercooked meat. Diagnostics include clinical symptoms, laboratory findings (eosinophilia, elevated muscle enzymes, and serology), and epidemiological investigations. Treatment options include albendazole or mebendazole monotherapy in case of mild or abortive disease [17].

Porcine trichinellosis in Ecuador is more common in traditional setting in villages compared to farms [18]. In 2015, only 8 cases of imported trichinellosis had been registered by the Robert-Koch-Institute (RKI) in Germany, all of European origin [11].

\section{Consent}

The examination of the patient was conducted according to the Declaration of Helsinki principles.

\section{REFERENCES}

1. Borges AF, Gomes RS, Ribeiro-Dias F. Leishmania (Viannia) guyanensis in tegumentary leishmaniasis. Pathog Dis. 2018;76. doi: $10.1093 /$ femspd/fty025.

2. Locatelli FM, Cajal SP, Barroso PA, Lauthier JJ, Mora MC, Juarez M, et al. The isolation and molecular characterization of Leishmania spp. from patients with American tegumentary leishmaniasis in northwest Argentina. Acta Trop. 2014;131:16-21.

3. Grimaldi G Jr, David JR, McMahon-Pratt D. Identification and distribution of New World Leishmania species characterized by serodeme analysis using monoclonal antibodies. Am J Trop Med Hyg. 1987;36:270-87.

4. Montalvo AM, Fraga J, Montano I, Monzote L, Van der Auwera G, Marín M, et al. Molecular identification of Leishmania spp. clinical isolates from Colombia based on hsp70 gene. Biomedica. 2016;36:37-44

5. Victoir K, De Doncker S, Cabrera L, Alvarez E, Arevalo J, LlanosCuentas A, et al. Direct identification of Leishmania species in biopsies from patients with American tegumentary leishmaniasis. Trans R Soc Trop Med Hyg. 2003;97:80-7.

6. Hashiguchi Y, Velez LN, Villegas NV, Mimori T, Gomez EAL, Kato H. Leishmaniases in Ecuador: Comprehensive review and current status. Acta Trop. 2017;166:299-315.
7. Weitzel T, Mühlberger N, Jelinek T, Schunk M, Ehrhardt S, Bogdan C, et al. Surveillance Importierter Infektionen in Deutschland (SIMPID) Surveillance Network. Imported leishmaniasis in Germany 2001-2004: data of the SIMPID surveillance network. Eur J Clin Microbiol Infect Dis. 2005;24:471-6.

8. Harms G, Scherbaum H, Reiter-Owona I, Stich A, Richter J. Treatment of imported New World cutaneous leishmaniasis in Germany. Int J Dermatol. 2011;50:1336-42.

9. Boecken G, Sunderkötter C, Bogdan C, Weitzel T, Fischer M, Müller A, et al. Germany Society of Dermatology; German Society of Tropical Medicine; German Society of Chemotherapy. Diagnosis and therapy of cutaneous and mucocutaneous Leishmaniasis in Germany. J Dtsch Dermatol Ges. 2011;9 (Suppl 8):1-51.

10. Wollina U, Koch A, Schönlebe J, Tchernev G, Chokoeva AA, Lotti T. Non-healing facial lesions: cutaneous old world leishmaniasis in Dresden. J Biol Regul Homeost Agents. 2015;29(1 Suppl):99-102.

11. Vygen-Bonnet S, Frank C, Stark K. Zur Situation bei wichtigen Infektionskrankheiten: Reiseassoziierte Krankheiten 2015. Epidemiologisches Bulletin des Robert-Koch-Instituts 2016;39:431-41.

12. Fonseca MS, Comini MA, Resende BV, Santi AM, Zoboli AP, Moreira DS, et al. Ornithine decarboxylase or gammaglutamylcysteine synthetase overexpression protects Leishmania (Vianna) guyanensis against antimony. Exp Parasitol. 2017;175:36-43.

13. Monte-Neto R, Laffitte MC, Leprohon P, Reis P, Frézard F, Ouellette M. Intrachromosomal amplification, locus deletion and point mutation in the aquaglyceroporin AQP1 gene in antimony resistant Leishmania (Viannia) guyanensis. PLoS Negl Trop Dis. 2015;9:e0003476.

14. Ives A, Ronet C, Prevel F, Ruzzante G, Fuertes-Marraco S, Schutz F, et al. Leishmania RNA virus controls the severity of mucocutaneous leishmaniasis. Science. 2011;331:775-8

15. Rossi M, Castiglioni P, Hartley MA, Eren RO, Prével F, Desponds C, et al. Type I interferons induced by endogenous or exogenous viral infections promote metastasis and relapse of leishmaniasis. Proc Natl Acad Sci USA. 2017;114:4987-92.

16. Bourreau E, Ginouves M, Prévot G, Hartley MA, Gangneux JP, Robert-Gangneux F, et al. Presence of Leishmania RNA Virus 1 in Leishmania guyanensis Increases the Risk of First-Line Treatment Failure and Symptomatic Relapse. J Infect Dis. 2016;213:105-11.

17. Gottstein B, Pozio E, Nöckler K. Epidemiology, diagnosis, treatment, and control of trichinellosis. Clin Microbiol Rev. 2009;22:127-45.

18. Chávez-Larrea MA, Dorny P, Moeller L, Benítez-Ortiz W, Barrionuevo-Samaniego M, Rodríguez-Hidalgo R, et al. Survey on porcine trichinellosis in Ecuador. Vet Parasitol. 2005;132:151-4.

Copyright by Uwe Wollina, et al. This is an open-access article distributed under the terms of the Creative Commons Attribution License, which permits unrestricted use, distribution, and reproduction in any medium, provided the original author and source are credited.

Source of Support: Nil, Conflict of Interest: None declared. 